\title{
Avaliação do efeito do alho (Allium sativum L.) sobre o colesterol plasmático em coelhos com hipercolesterolemia induzida
}

\author{
KLASSA, B.*; GROSSELI, M.M.; KIYOMURA, A.K.; ALVES, M.J.Q.F. \\ Departamento de Fisiologia, Instituto de Biociências, Unesp, Campus de Botucatu, CEP: 18618-000, Botucatu- \\ Brasil *bklassa@gmail.com
}

\begin{abstract}
RESUMO: A utilização de plantas no tratamento de doenças ou como meio curativo é uma tradição popular e altamente difundida, sendo que muitos trabalhos abordam as propriedades terapêuticas e farmacológicas do alho na redução das hiperlipidemias. O objetivo deste estudo foi investigar a influência do extrato aquoso (E.A.) do alho (Allium sativum L.) no tratamento do colesterol plasmático em coelhos com hipercolesterolemia experimental. Os animais foram divididos em G1 (grupo controle) e G2 (grupo tratado com alho). O experimento foi desenvolvido em três fases: na 1a fase os animais receberam dieta comercial de coelhos para avaliar o nível basal de colesterol nos animais; na $2^{\text {a }}$ fase, todos os animais passaram a receber dieta suplementada com gema de ovo, até o final do experimento, para desenvolver hipercolesterolemia, e; na $3^{\text {a }}$ fase os animais do grupo $\mathrm{G} 2$ receberam o tratamento com $\mathrm{E}$. A. de alho. O colesterol na 1a fase foi de $39,94 \pm 9,57 \mathrm{mg} \mathrm{dL}^{-1}$. Na $2^{\mathrm{a}}$ fase houve elevação significativa $(p<0,05)$ no nível de colesterol plasmático nos dois grupos - acima de $100 \mathrm{mg}$ $\mathrm{dL}^{-1}$. Com relação ao tratamento, o alho não promoveu redução no colesterol plasmático dos coelhos, contrapondo os dados da literatura.
\end{abstract}

Palavras-chave: Allium sativum, alho, coelho, hipercolesterolemia

\begin{abstract}
Evaluation of garlic (Allium sativum L.) effects on the serum cholesterol of rabbits with induced hypercholesterolemia. The use of plants to treat diseases or even to cure them is a high diffused popular tradition, and several studies discuss the therapeutic and pharmacological properties of garlic in the reduction of hyperlipidaemias. The objective of the present study was to investigate the influence of the aqueous extract of garlic (Allium sativum) to treat the serum cholesterol of rabbits with experimental hypercholesterolemia. The animals were divided into G1 (control group) and G2 (group treated with garlic). The experiment was developed according to 3 phases: during the $1^{\text {st }}$ phase, all animals were provided with a regular diet to evaluate the basal cholesterol; during the $2^{\text {nd }}$ phase, all animals received a supplemented diet until the end of the experiment, in order to develop hypercholesterolemia and, in the $3^{\text {rd }}$ phase, the animals on $\mathrm{G} 2$ received the garlic treatment. The cholesterol registered on the $1^{\text {st }}$ phase was $39.94 \pm 9.57 \mathrm{mg} \mathrm{dL}^{-1}$. On the $2^{\text {nd }}$ phase, there was an increase on the serum cholesterol level in both groups - higher than $100 \mathrm{mg} \mathrm{dL}^{-1}$. Concerning the treatment, the garlic did not reduce the serum cholesterol in rabbits.
\end{abstract}

Keywords: Allium sativum, garlic, hypercholesterolemia, rabbits

\section{INTRODUÇÃO}

A hipercolesterolemia tem sido apontada como uma das principais causas das doenças cardiovasculares, que são responsáveis por $20 \%$ das mortes em todo o mundo (Ostlund et al., 2004; Patel \& Thompson, 2006). Segundo a Sociedade Brasileira de Cardiologia (Sposito et al., 2007), o aumento do colesterol está presente em aproximadamente um quinto da população brasileira, especialmente em pessoas com mais de 45 anos, devido ao tipo de vida que se tornou prevalente nos dias atuais, com alimentação inadequada e hábito sedentário. $\mathrm{O}$ aumento da taxa de colesterol total no sangue pode ser associado à obesidade, alta ingestão de alimentos ricos em colesterol, baixa ingestão de fibras ou ainda ser problema de ordem genética, manifestado por maior produção endógena de colesterol (Sposito et al., 2007).

As doenças cardiovasculares continuam

Recebido para publicação em 24/03/2011

Aceito para publicação em 22/02/2013

Rev. Bras. PI. Med., Campinas, v.15, n.4, p.557-565, 2013. 
constituindo a maior causa de morbidade e mortalidade, apesar dos significativos avanços tanto no diagnóstico quanto no tratamento realizados nas últimas décadas (Stamler et al., 1993; Giugliano et al., 1996; Ostlund et al., 2004; Kojuri et al., 2007). A prevenção dessas doenças envolve o conhecimento dos fatores de risco, cujo controle diminui sua incidência (Praça et al., 2004). Sendo assim, uma medida importante para o tratamento desta patologia que envolve a hipercolesterolemia é a redução da ingestão de alimentos com alto teor de gorduras saturadas (de origem animal), ricas em colesterol, associada à incorporação de alimentos com ação preventiva na dieta.

Hoje existem diferentes tipos de medicamentos de origem sintética capazes de normalizar as hiperlipidemias. Porém se este tratamento é eficiente, também é caro e não isento de efeitos colaterais, proporcionais à dose do medicamento utilizado (Gonçalves et al., 2000). Neste contexto, mais de $80 \%$ da população, nos países em desenvolvimento, usa a medicina tradicional (acupuntura, terapias manuais e plantas medicinais) como cuidado básico da saúde, seja por tradição cultural, por falta de alternativas (Kiss et al., 2006), seja pelo fato de causarem menos efeitos colaterais em relação aos medicamentos alopáticos, apresentando às vezes, efeitos terapêuticos superiores a esses. No Brasil, a utilização de plantas como meio curativo é uma atividade altamente difundida e popular, sendo empregada pelos povos desde tempos antigos (Verpoorte, 1998). O uso de medicamentos naturais como o alho tem se tornado uma alternativa preventiva e de tratamento para variados males (Drobiova et al., 2009).

A espécie Allium sativum L. (Liliaceae), conhecida popularmente como alho, pertence à família das Liliáceas e é nativa da Ásia Central, cultivada em vários países, sendo amplamente conhecida no Brasil. Além de ser considerada um ingrediente de significativa importância na culinária e economicamente acessível, é rica em compostos sulfurados e possui alta concentração de fitoquímicos terapêuticos localizados nos bulbos (Heizmann, 2001). Segundo Marchiori (2003), já foram identificados cerca de 30 componentes do alho com efeitos terapêuticos para a saúde. Algumas dessas propriedades farmacológicas estão bem estabelecidas, como ação antibacteriana (Di Stasi, 1996; Cutler \& Wilson, 2004), antioxidante (Drobiova et al., 2009), fibrinolítica (Robbers et al., 1996; Rahman, 2001), anticoagulante e antihipertensiva (Mashour et al., 1998; Al-Qattan et al., 2003), natriurético e diurético (Pantoja et al., 2000), estimulante da secreção de insulina e ação hipoglicêmica (Augusti \& Sheela, 1996), ação hipolipidêmica (Ismail et al., 1999), além de prevenção da arteriosclerose (Durak et al., 2002).

A ação preventiva do alho quanto às doenças cardiovasculares é reconhecida (Bordia et al., 1998; Sobenin et al., 2008), e nos últimos anos, atenção particular tem sido dedicada para sua atividade na redução do colesterol. Vários estudos (Bordia et al., 1975; Jain, 1977; Augusti, 1977; Bordia et al., 1977; Sainani et al., 1979; Nityanand et al., 1989) têm mostrado que este vegetal possui componentes hipocolesterolêmicos. Relatos da literatura médica ao longo dos últimos 20 anos sugerem que a suplementação da dieta com alho pode ser efetiva no decréscimo dos níveis séricos de colesterol em 15 a $20 \%$. No entanto, eles variam significativamente em termos de efeito do tratamento, tipos de preparações, dosagem e unidade experimental utilizada (Warshafsky et al., 1993; Marchiori, 2003; Rahman \& Lowe, 2006; Sobenin et al., 2008), sendo que a forma de utilização é fundamental para que haja princípios ativos em concentrações suficientes para exercerem a ação terapêutica. Talvez, este seja o motivo pelo qual alguns estudos não corroborem sobre a diminuição do nível de lipídios no sangue (Brace, 2002). Neste contexto, objetivou-se com este trabalho investigar o efeito do extrato aquoso do alho sobre o nível sérico de colesterol em coelhos hipercolesterolemia induzida.

\section{MATERIAL E MÉTODO}

\section{Condições gerais do experimento}

Os experimentos foram realizados com seis coelhos (Oryctolagus cuniculus) machos, pesando em torno de $1.300 \mathrm{~g}$, obtidos no Biotério Central da UNESP/Botucatu. Os animais foram mantidos em gaiolas metabólicas individuais e numeradas, no Biotério do Departamento de Fisiologia, Instituto de Biociências-UNESP/Botucatu, durante todo o decorrer do experimento, recebendo água e ração apropriada a cada grupo experimental.

Utilizou-se extrato aquoso de alho (espécie Allium sativum Linn.), obtido pelo método de decocção, na concentração de $5 \%$. O alho foi obtido em lojas comerciais de Botucatu e reconhecido pelo Herbário Irina Delanova Gemthújnicov - BOTU, da UNESP (número 25145). Os extratos foram preparados no Departamento de Fisiologia do Instituto de Biociências da UNESP/Botucatu.

\section{Formulação da ração}

A ração suplementada e fornecida aos animais foi formulada pelo Laboratório de Cirurgia Experimental da Faculdade de Medicina da UNESP/ Botucatu. Essa dieta foi preparada a partir da ração comercial para coelhos na seguinte proporção: 12,5 $\mathrm{kg}$ de ração triturada, $1.187 \mathrm{~g}$ de gema de ovos e 
$1.187 \mathrm{~mL}$ de óleo de milho. A ração comercial foi moída em triturador e acrescida com as gemas de ovo e o óleo. Adicionou-se água à mistura até adquirir consistência de massa. A partir dessa mistura os péletes foram confeccionados e desidratados em estufa com circulação de ar forçada a $60^{\circ} \mathrm{C}$ durante 24h (Fernandes et al., 2002; Mesquita et al., 2007).

\section{Grupos Experimentais}

Inicialmente, antes da realização do experimento, todos os animais foram mantidos durante sete dias no Biotério do Departamento de Fisiologia, com a finalidade de adaptarem-se ao novo ambiente (onde permaneceram até o final de experimento). Neste período os animais receberam água e ração comercial ad libitum. Os animais, escolhidos aleatoriamente, foram numerados a fim de formar os grupos experimentais: G1 e G2, conforme a Tabela 1.

$\mathrm{Na}$ primeira fase, todos os animais receberam ração comercial e água, para registrar o nível fisiológico de colesterol. Após esse período iniciou-se a suplementação e os animais passaram a receber a ração enriquecida até o final do experimento, a fim de promover a hipercolesterolemia e mantê-la. Uma vez estabelecido o aumento do nível de colesterol, o grupo tratado (G2) iniciou o tratamento com o extrato aquoso de alho e o grupo controle recebeu água.

\section{Condução do experimento}

Os animais receberam diariamente $200 \mathrm{~g}$ de ração e $150 \mathrm{~mL}$ de água e tratamento, conforme descrito anteriormente. $O$ peso dos animais foi obtido num intervalo de 15 dias e para a avaliação do colesterol, o sangue foi coletado semanalmente, através da veia marginal da orelha dos coelhos. Durante a coleta de sangue, após jejum de 14 horas, os animais foram colocados em uma caixa de contenção apropriada para coelhos. Uma agulha pré - heparinizada foi introduzida na veia marginal de modo que o sangue drenasse livre e diretamente para o tubo de ensaio (próprio de centrifuga), evitando assim hemólise. O plasma, obtido através de centrifugação do sangue a $3.000 \mathrm{rpm}$ por 15 minutos, foi armazenado para posteriores dosagens das frações lipídicas, isto é, colesterol total, HDL e LDL colesterol. Essas dosagens foram feitas por meio de kits enzimáticos.

\section{Eutanásia}

A eutanásia foi realizada por meio de deslocamento cervical (decapitação) e o protocolo está de acordo com os Princípios Éticos na Experimentação Animal, sendo aprovado em reunião pela Comissão de Ética na Experimentação Animal do Instituto de Biociências de Botucatu (protocolo no 205-CEEA).

\section{Análise Estatística}

Para cada variável analisada no experimento foram feitos dois testes: o primeiro consistiu na análise multivariada de perfil (Morrison, 1990), que visa comparar o efeito de momentos para cada grupo. Foram considerados 7 momentos, o M0 (valores médios obtidos na última semana de suplementação - 2a fase) e os demais momentos (M1, M2, M3, M4, M5 e M6), que correspondem aos valores médios obtidos desde a primeira até a sexta semana de tratamento - 3a fase.

$O$ segundo teste utilizado foi o Teste $U$ de Mann - Whitney. Este toma por base as diferenças absolutas dos pares de observação das amostras, isto é, a diferença entre os valores obtidos no tratamento e no período de suplementação. O Teste $U$ é usado nas mesmas condições que o Teste $t$, porém é mais sensível, oferecendo probabilidades mais exatas para experimentos com poucas amostras. O nível de significância adotado para ambos os testes foi de $5 \%$.

\section{RESULTADOS E DISCUSSÃO}

A Tabela 2 mostra os resultados obtidos com a evolução de ingestão diária média (em gramas), durante as três fases experimentais para os coelhos dos grupos G1 (grupo controle) e G2 (grupo tratado com alho). Os valores médios do aumento de peso corporal dos animais de cada grupo experimental estão representados na Figura 1. Não houve diferença significativa $(p>0,05)$ entre os grupos, porém a diferença entre $\mathrm{F} 1$ e F3 foi significativa $(p<0,05)$.

A Tabela 3 e as Figuras 2 e 3 mostram os valores médios de colesterol total nos dois grupos, durante os três períodos experimentais.

TABELA 1. Delineamento experimental. F1, F2 e F3 correspondem respectivamente às fases experimentais 1,2 e 3.

\begin{tabular}{cccc}
\hline Grupos Experimentais & F1 (42 dias) & F2 (61 dias) & F3 (42 dias) \\
\hline G1-controle $(n=3)$ & Ração normal & Ração suplementada & Ração suplementada \\
G2-tratado $(n=3)$ & Ração normal & Ração suplementada & Ração suplementada + tratamento \\
\hline
\end{tabular}


TABELA 2. Ingestão média de ração (em gramas) dos grupos G1 e G2 durante as três fases da experimentação.

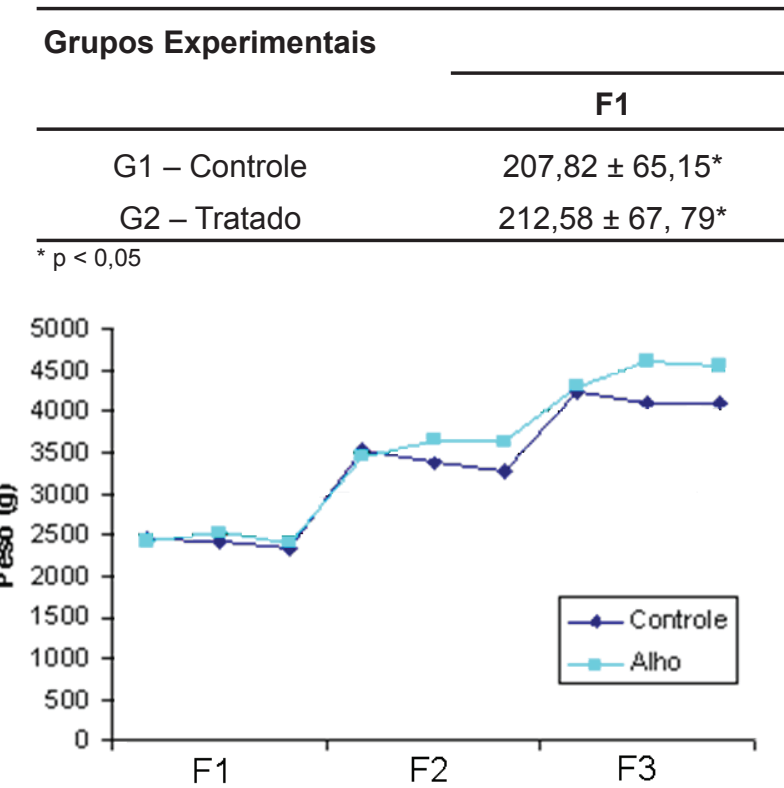

FIGURA 1. Peso médio dos coelhos dos grupos $\mathrm{G} 1$ e G2 durante as três fases do experimento.

Os animais, na primeira fase apresentaram uma taxa média de colesterol de 30 e $50 \mathrm{mg} \mathrm{dL}^{-1}(\mathrm{G} 1$ e G2, respectivamente), considerada normal (Fernandes et al., 2002; Mesquita et al., 2007; Alves et al., 2008). Os coelhos dos dois grupos elevaram significativamente $(p<0,05)$ o colesterol na $2^{2}$ fase (com ração suplementada). A suplementação da $3^{a}$ fase continuou aumentando o colesterol de todos os animais, e não houve redução significativa do nível de colesterol plasmático dos coelhos tratados com alho em relação aos coelhos do grupo controle $(p>0,05)$. As 3 fases experimentais foram significativamente diferentes entre si ( $\left.{ }^{*} p<0,05\right)$, entretanto, não houve diferença significativa entre os grupos em cada fase $(p>0,05)$ (Teste $U$ de Mann Whitney). A tabela 4 mostra que não houve diferença significativa entre os momentos de $\mathrm{M} 0$ a M6.

As Figuras 4 e 5 mostram os valores médios de HDL e LDL ( $\mathrm{mg} \mathrm{dL}^{-1}$ ), respectivamente, para os animais dos grupos G1 e G2. Não houve diferença significativa nos valores de HDL plasmático ao longo do experimento (três fases), assim como entre os grupos, apesar de notar-se um aumento do HDL no
Fases

F2

$181,94 \pm 69,44$

$173,23 \pm 75,26$

$113,81 \pm 57,28^{*}$

$113,71 \pm 51,661^{*}$

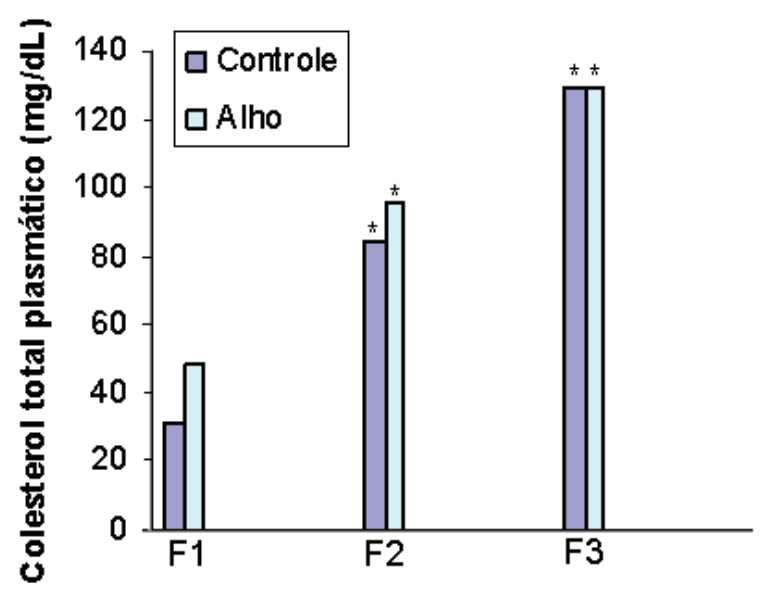

FIGURA 2. Progressão do colesterol total plasmático dos coelhos ao longo do experimento (durante as três fases).

grupo tratado na F3 (de 27,54 para 46,97 mg.dL-1). A suplementação com ração rica em gema de ovo elevou significativamente o LDL das $2^{\mathrm{a}}$ e $3^{\mathrm{a}}$ fases nos dois grupos $(p<0,05)$ em relação à primeira fase, mas o tratamento não modificou o nível de LDL no plasma dos coelhos $(p>0,05)$. No entanto, na fase 3 , nota-se diminuição dessa fração em G2 (de 106,04 para $\left.91,80 \mathrm{mg} \cdot \mathrm{dL}^{-1}\right)$.

Todos os coelhos (grupos G1 e G2) ganharam peso na mesma proporção, não apresentando diferenças significativas $(p>0,05)$, o que sugere que a suplementação e o tratamento não interferiram no ganho de peso corporal dos animais (Figura 1). Observando os resultados de ingestão de ração (Tabela 2), notou-se que os animais de ambos os grupos diminuíram o consumo diário de ração, da 1a para a $3^{a}$ fase. Isso pode ocorrer devido o confinamento a que os coelhos foram submetidos e o stress causado a esses animais, o que pode reduzir a procura por alimento (Mesquita

TABELA 3. Valores médios obtidos para o nível plasmático de colesterol total $\left(\mathrm{mg} \mathrm{dL}^{-1}\right)$ dos coelhos, avaliados nas três fases. $2^{\mathrm{a}}$ e $3^{\mathrm{a}}$ fases são significativamente diferentes da $1^{\mathrm{a}}$ fase.

\begin{tabular}{cccc}
\hline Grupos Experimentais & \multicolumn{3}{c}{ Fases } \\
\cline { 2 - 4 } & F1 & F2 & F3 \\
\hline G1 - Controle & $30,76 \pm 6,67$ & $84,04 \pm 42,87^{*}$ & $129,69 \pm 33,31^{*}$ \\
G2 - Tratado & $49,12 \pm 12,48$ & $95,93 \pm 22,12^{*}$ & $129,23 \pm 29,45^{\star}$ \\
\hline${ }^{*} p<0,05$ & &
\end{tabular}


TABELA 4. Valores médios obtidos para o nível plasmático de colesterol total ( $\mathrm{mg} / \mathrm{dL})$ dos coelhos nos momentos considerados (M0 a M6).

\begin{tabular}{cccc}
\hline Grupos Experimentais & G1 - Controle & G2 - Tratado \\
\hline & M0 & $120,43 \pm 31,41$ & $120,43 \pm 31,41$ \\
& M1 & $70,75 \pm 35,48$ & $121,50 \pm 23,94$ \\
& M2 & $162,58 \pm 111,99$ & $140,86 \pm 127,70$ \\
& M3 & $111,01 \pm 37,44$ & $96,71 \pm 19,68$ \\
& M4 & $119,88 \pm 81,71$ & $149,64 \pm 90,45$ \\
& M5 & $146,49 \pm 91,06$ & $120,45 \pm 18,19$ \\
& M6 & $167,38 \pm 67,42$ & $171,38 \pm 51,28$ \\
\hline
\end{tabular}

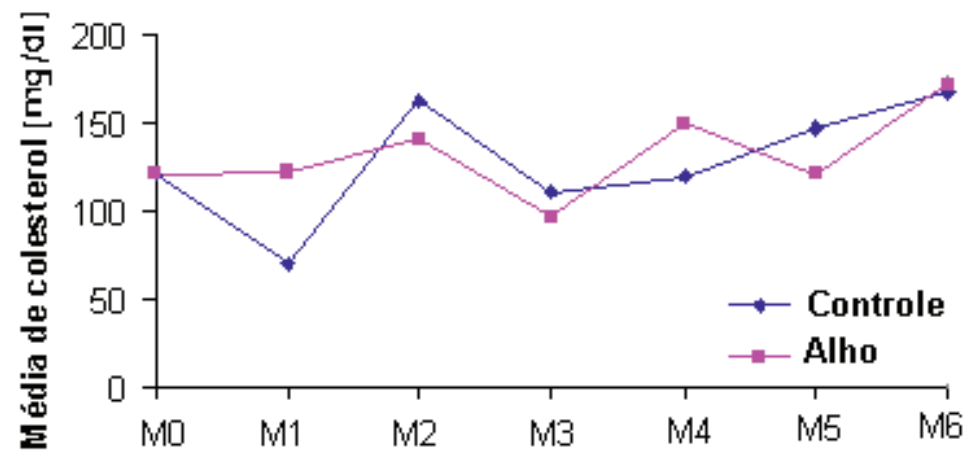

FIGURA 3. Progressão do colesterol total plasmático dos coelhos desde a última semana da Fase 2 (M0) até o final do experimento (M1 a M6 - Fase 3). Não houve diferença significativa entre cada momento $(p>0,05)$ (Análise Multivariada de Perfil).

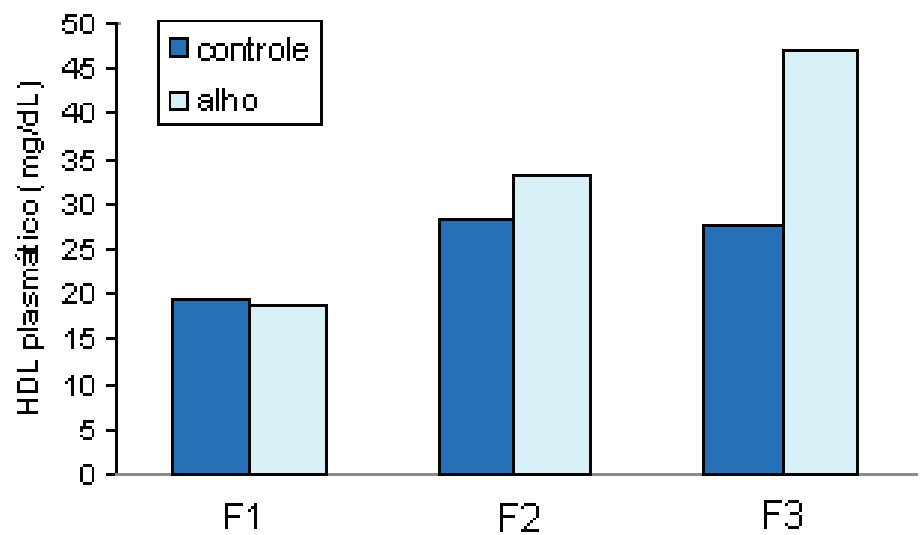

FIGURA 4. O eixo vertical do gráfico mostra os valores médios de HDL (mg.dL-1 $)$ plasmático, nos 3 períodos da experimentação, nos 2 grupos: G1 e G2. Os resultados não diferiram estatisticamente ( $p>0,05)$. 


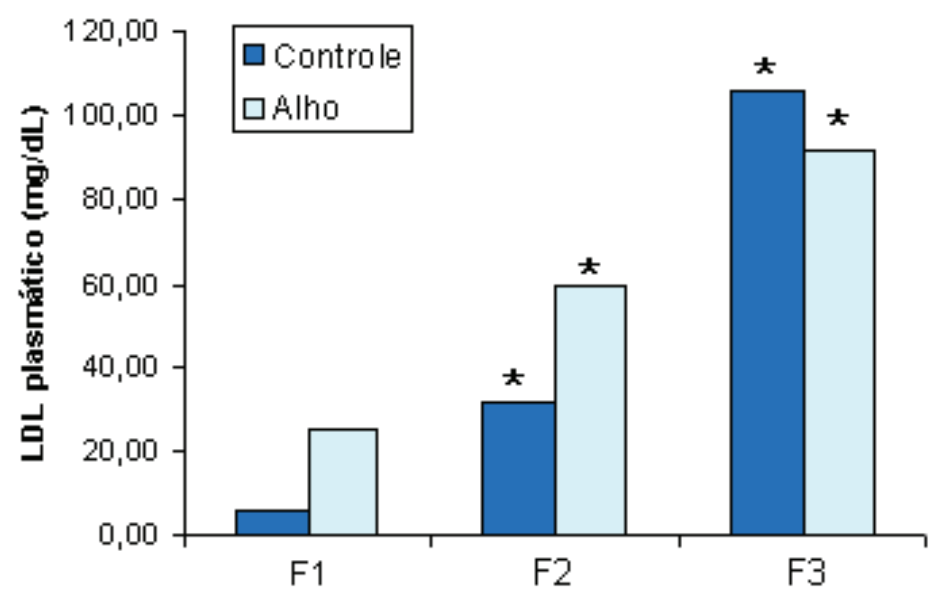

FIGURA 5. O eixo vertical do gráfico mostra os valores médios de LDL ( $\mathrm{mgdL}^{-1}$ ) plasmático, nos 3 períodos da experimentação, nos 2 grupos: G1 e G2. As $2^{\mathrm{a}}$ e $3^{\mathrm{a}}$ fases dos dois grupos foram estatisticamente diferentes da 1 a fase $\left({ }^{*} p<0,05 \%\right)$. Não houve diferença significativa entre os grupos $(p>0,05)$.

et al., 2007). Resultados apresentados por Pittas et al. (1999) mostraram que a ração suplementada é hipercalórica, o que poderia explicar a diminuição da ingestão dos animais mantendo, porém, ganho de peso progressivamente. Não houve diferença na terceira fase, quando comparados os animais tratados e não tratados, o que sugere que o extrato aquoso de alho não interferiu no ganho de peso (Figura 1). As tabelas 3 e 4 e as figuras 2 e 3 apresentam os valores médios do colesterol total para os coelhos do G1 e G2.

Foram analisados os animais tratados com extrato aquoso de alho (grupo G2) segundo os testes descritos na metodologia. A análise do Teste $U$ mostrou aumento significativo no nível plasmático do colesterol total $(p<0,05)$ da $1^{a}$ fase para as demais, corroborando os dados da literatura (Fernandes et al., 2002; Mesquita et al., 2007; Alves et al., 2008), os quais mostraram que a ração suplementada foi eficiente em induzir a hipercolesterolemia em coelhos. Segundo Sherr \& Ribeiro (2008), $100 \mathrm{~g}$ de ovos apresentam em média $400 \mathrm{mg}$ de colesterol, ultrapassando o recomendado que é até $300 \mathrm{mg} \mathrm{dia}^{-1}$, o que respalda a utilização da ração suplementada na indução da hipercolesterolemia. O nível de colesterol aumentou na mesma proporção nos animais de G1 e G2 e não houve diferença entre os grupos $(p>0,05)$ (tabela 3 e figura 2). Os valores obtidos na análise multivariada de perfil nos diferentes momentos (última semana de suplementação - M0 - e todas as semanas de tratamento - M1 a M6) também não diferiram estatisticamente entre si $(p>0,05)$ (Tabela 4 e figura 3).

Quanto aos níveis de HDL e LDL, a fase de tratamento também não diferiu estatisticamente da fase de suplementação. Apresentou-se diferença significativa $(p<0,05)$ apenas nos níveis de LDL dos coelhos entre a $1^{\mathrm{a}}$ fase e as demais (Figura 5). Entretanto, observa-se tendência em aumento das frações de HDL e diminuição das frações de LDL no grupo tratado com extrato aquoso de alho (G2) (Figuras 4 e 5). Essa tendência, mesmo não sendo significativa, é importante, pois sugere o efeito terapêutico do alho, aumentando os níveis de HDL - fração responsável pelo transporte de 20 a $25 \%$ do colesterol do sangue para tecidos e fígado - (Millner, 1990; Whitney, 1994) e diminuindo os níveis de LDL, que transportam a maior parte do colesterol (75 a 80\%) no sangue e depositam-no nas células e nas paredes das artérias, reduzindo o fluxo sanguíneo e, consequentemente, o oxigênio que chega ao coração (Sposito, 2007). Elevados níveis de LDL representam um grande risco para doenças coronarianas, relacionando-se diretamente com o desenvolvimento da arteriosclerose (induzindo à formação da placa ateromatosa) (Fernandes et al., 2002; Liu et al., 2009), podendo desencadear uma série de desordens no sistema cardiovascular como angina, infarto do miocárdio, acidente vascular cerebral, hipertensão, insuficiência cardíaca, doença arterial coronariana e outras (Sposito, 2007). Talvez com a utilização de um período de tratamento maior essa tendência observada se mostre estatisticamente significativa.

A escolha da concentração do extrato aquoso de alho (5\%) foi aleatória, não seguindo nenhum protocolo experimental, podendo assim ser responsável pela ineficácia de $A$. sativum em reduzir o colesterol nos animais deste estudo. Diversos trabalhos que utilizaram concentrações maiores mostraram sucesso na redução do colesterol

Rev. Bras. PI. Med., Campinas, v.15, n.4, p.557-565, 2013. 
plasmático pelo alho (McCrindle et al., 1998; Baluchnejadmojarad et al., 2002; Kiss et al., 2006, Kojuri et al., 2007; Drobiova et al., 2009).

Outra possibilidade que pode explicar a ausência de efeito do alho pode estar relacionada à forma escolhida para tratamento - extrato aquoso obtido pelo método de decocção. Talvez este método tenha impedido a liberação dos agentes hipocolesterolêmicos (compostos organosulfurados) do alho. A maioria dos componentes sulfurados não está presente nas células intactas, e somente quando o dente de alho é amassado, triturado ou mastigado, esses componentes são liberados no interior da célula vegetal (Marchiori, 2003; Leonêz, 2008). De fato, alguns trabalhos obtiveram o extrato aquoso após trituração dos bulbos no liquidificador (Aouadi et al., 2000; Baluchnejadmojarad et al., 2002; Kiss et al., 2006; Drobiova et al., 2009). Neste trabalho, o alho foi apenas picado em pedaços menores, sem, no entanto, ser triturado.

Além disso, Marchiori (2003) relatou que qualquer ação de calor ou outro tipo de tratamento térmico diminui muito as concentrações dos fitoquímicos sulfurados em questão, e como o método de decocção consiste em levar o material vegetal e o solvente (neste caso, água) ao fogo até a fervura e manter em infusão por 15 minutos, esta pode ser outra razão para a manutenção dos altos níveis de colesterol no período do tratamento. Segundo Banerjee \& Maulik (2002), a alicina é o principal composto bioativo presente no extrato aquoso do alho ou no alho cru, e a enzima aliinase, responsável pela conversão de aliina em alicina, é inativada pelo calor.

Outra hipótese para o resultado desfavorável do alho nesse estudo foi o período de tratamento utilizado relativamente curto, de 42 dias. Outros estudos que obtiveram sucesso foram realizados com tratamento entre 80 e 90 dias (Bordia et al., 1998; Aouadi et al., 2000). Talvez 42 dias tenham sido insuficientes para os componentes do alho fazerem efeito, apesar de Kiss et al. (2006) ter conseguido bons resultados com apenas 28 dias de tratamento. Este trabalho motiva um novo estudo utilizando extrato aquoso de alho macerado e um período de tratamento maior.

\section{CONCLUSÃO}

Os resultados apresentados não permitem concluir sobre a eficacia do alho (Allium sativum) nas condições experimentais propostas, em reduzir o colesterol total plasmático, em coelhos submetidos à hipercolesterolemia experimental. Sendo assim, sugerimos que outros estudos mais elaborados sejam realizados, testando diferentes formas de extrato, por exemplo a partir do alho triturado, e utilizando uma maior amostragem de animais.

\section{REFERÊNCIA}

ALVES, M.J.Q.F. et al. Efeito hipocolesterolêmico dos ácidos cafeicos da própolis. Revista Brasileira de Plantas Medicinais, v.10, n.1, p.100-5, 2008.

AL-QATTAN, K.K. et al. Mechanism of garlic (Allium sativum) induced reduction of hypertension in $2 \mathrm{~K}-1 \mathrm{C}$ rats: a possible mediation of $\mathrm{Na} / \mathrm{H}$ exchanger isoform- 1 . Prostaglandins, Leukotrienes and Essential Fatty Acids, v.69, n.4, p.217-22, 2003.

AOUADI, R. et al. Effect of fresh garlic (Allium sativum) on lipid metabolism in male rats. Nutrition Research, v.20, n.2, p.273-80, 2000.

AUGUSTI, K.T.; SHEELA, C.G. Antiperoxide effect os sallylcysteine sulfoxide, an insulin secretagogue, in diabetic rats. Experientia, v.52, n.2, p.115-20, 1996.

AUGUSTI, K.T. Hypocholesterolaemic effect of garlic Allium sativum Lin. Indian Journal of Experimental Biology, v.15, n.6, p.489-90, 1977.

BALUCHNEJADMOJARAD, T. et al. Beneficial effect of aqueous garlic extract on the vascular reactivity of streptozotocin-diabetic rats. Journal of Ethnopharmacology, v.85, n.1, p.139-44, 2002.

BANERJEE, S.K.; MAULIK, S.K. Effect of garlic on cardiovascular disorders: a review. Nutrition Journal, v.1, n.4, p.135-49, 2002.

BORDIA, A. et al. Effect of the essential oils of garlic and onion on alimentary hyperlipemia. Atherosclerosis, v.21, n.1, p.15-9, 1975.

BORDIA, A. et al. The effective of active principle of garlic and onion on blood lipids and experimental atherosclerosis in rabbits and their comparison with clofibrate. Journal of Association of Physicians of India, v.25, n.8, p.509-16, 1977.

BORDIA, A. et al. Effect of garlic (Allium sativum) on blood lipids, blood sugar, fibrinogen and fibrinolytic activity in patients with coronary artery disease. Prostaglandins, Leukotrienes and Essential Fatty Acids, v.58, n.4, p.257-63, 1998.

BRACE, L.D. Cardiovascular benefits of garlic (Allium sativum L.). The journal of Cardiovascular Nursing, v.16, n.4, p.33-49, 2002.

CUTLER, R.R.; WILSON, P. Antibacterial activity of a new stable aqueous extract of allicin against methicillinresistant Staphylococcus aureus. British Journal of Biomedical Science, v.61, n.2, p.71-4, 2004.

Di STASI, L.C. Arte, ciência e magia. In: Di Stasi, L.C. (Ed.). Plantas medicinais: arte e ciência. Um guia de estudo interdisciplinar. São Paulo: Editora Unesp, 1996, p.15-27.

DROBIOVA H. et al. Garlic increases antioxidant levels in diabetic and hypertensive rats determined by a modified peroxidase method. Evidence-based Complementary and Alternative Medicine, volume 2011, article ID 703049, doi:10.1093/ecam/nep011, 2009.

DURAK, I. et al. Effects of garlic extract supplementation on blood lipid and antioxidant parameters and atherosclerotic

Rev. Bras. PI. Med., Campinas, v.15, n.4, p.557-565, 2013. 
plaquet formation process in cholesterolfed rabbits. Journal of Herbal Pharmacotherapy, v.2, n.2, p.1932, 2002.

FERNANDES, A.A.H. et al. Avaliação do colesterol plasmático em coelhos com hipercolesterolemia induzida e tratados com extrato etanólico de própolis. Revista Brasileira de Plantas Medicinais, v.4, n.2, p.1-5. 2002.

GIULIANO, D. et al. Oxidative stress and diabetic vascular complications. Diabetes Care, v.19, n.3, p.257-67, 1996.

GONÇALVES, M.C.R. et al. Produtos naturais inibidores da enzima HMG CoA redutase. Revista Brasileira de Farmácia, v.81, n. 3, p.63-71, 2000.

HEIZMANN, B.M. Compostos de enxofre. In: Simões, C.M.O. Farmacognosia: da planta ao medicamento. 3ed. Florianópolis: Editora da UFSC. 2001. p.63350.

ISMAIL, M.F. et al. Study of the hypolipidemic properties of pectin, garlic and ginseng in hypercholesterolemic rabbits. Pharmacological Research, v.39, n.2, p.15766, 1999.

JAIN, R.C. Effect of garlic on serum lipids, coagulability and fibrinolytic activity of blood. American Journal of Clinical Nutrition, v.30, n.9, p.1380-1, 1977.

KISS, A.C.I. et al. Efeito do extrato aquoso de Allium sativum L. sobre parâmetros bioquímicos de ratas com diabete induzido por Streptozotocin. Revista Brasileira Plantas Medicinais, v.8, n.3, p.24-30, 2006.

KOJURI, J. et al. Effects of anethum graveolens and garlic on lipid profile in hyperlipidemic patients. Lipids in Health and Disease, v.6, n.5, p.24-9, 2007.

LEONÊZ, A.C. Alho: alimento e saúde. 2008. 30p. Monografia (Pós-graduação lato sensu - Área de concentração em Gastronomia e Saúde) - Centro de Excelência em Turismo, Universidade de Brasília, Brasília.

LIU, X. et al. Effect of plant sterol-enriched diets on plasma and egg yolk cholesterol concentrations and cholesterol metabolism in laying hens. Metabolism and Nutrition, v.89, p.270-75, 2009.

MARCHIORI, V.F. Alho - descubra como o alho pode favorecer muito a sua saúde. 1.ed. São Paulo: Scortecci Editora, 2005. 72p.

MASHOUR, N.H. et al. Herbal medicine for the treatment of cardiovascular disease. Archives of Internal Medicine, v.158, n. 20, p.2225-34, 1998.

MCCRINDLE, B.W. et al. Garlic extract therapy in children with hypercholesterolemia. Archives of Pediatrics \& Adolescent Medicine, v.152, n.11, p.1089-94, 1998.

MESQUITA, F.F. et al. Efeitos da fração flavonóidica da própolis sobre o metabolismo de colesterol, em coelhos com hipercolesterolemia experimental. Revista Brasileira de Plantas Medicinais, v.9, n.1, p.44-50, 2007.

MILLNER, N.E. Raising high density lipoprotein cholerterol:the biochemical pharmacology of reverse cholesterol transport. Biochemical Pharmacology, v.40, p.403-10, 1990.

MORRISON, D.F. Multivariate statistical methods. São Paulo: Mc Graw - Hill, 1990. 450p.
NITYANAND, S. et al. Clinical trials with 'Gugulipid': a new hypolipidaemic agent. Journal of Association of Physicians of India, v.37, n.5, p.323-8, 1989.

OSTLUND, R.E. et al. Phytosterols and cholesterol metabolism. Current Opinion in Lipidology, v.15, n.1, p.37-41, 2004.

PANTOJA, C.V. et al. Purification and bioassays of a diuretic and natrutetic fraction from garlic (Allium sativum). Journal of Ethnopharmacology, v.70, n.1, p.35-40, 2000.

SINGI, G. et al. Efeitos agudos dos extratos hidroalcoólicos do alho (Allium sativum L.) e do capimlimão (Cymbopogon citratus (DC) Stapf) sobre a pressão arterial média de ratos anestesiados. Revista Brasileira Farmacognosia, v.15, n.2, p.94-7, 2005.

PATEL, M.D.; THOMPSON ,P.D. Phytosterols and vascular disease. Artherosclerosis, v.186, n.1, p.12-9, 2006.

PITTAS, A.M.C.S. et al. Níveis de colesterol plasmáticos em coelhos submetidos à ração normal e suplementada. ENCONTRO REGIONAL DE BIOMEDICINA, 2., 1999. Botucatu. Anais... Botucatu, 1999.

PRAÇA, M.J. et al. O suco de berinjela (Solanum melongena) não modifica os níveis séricos de lípides. Arquivo Brasileiro de Cardiologia, v.82, n.3, p.26972, 2004.

RAHMAN, K. Historical perspective on garlic and cardiovascular disease. Journal of Nutrition, v.131, n.3S, p.977S-9S, 2001.

RAHMAN, K.; Lowe, G.M. Garlic and cardiovascular disease: a critical review. Journal of Nutrition, v.136, suppl.3, p.736S-40S, 2006.

ROBBERS, J.E. et al. Pharmacognosy and Pharmacobiotechnology. 9.ed. Baltimore: Williams \& Wilkins, 1996, p.337.

SAINANI, G.S. et al. Effect of dietary garlic and onion on serum lipid profile in Jain community. Indian Journal of Medical Research, v.69, p.776-80, 1979.

SHERR, C.; RIBEIRO, J.P. Colesterol e gorduras em alimentos brasileiros: implicações para a prevenção da aterosclerose. Arquivos Brasileiros de Cardiologia, v.92, n.3, p.190-4, 2008.

SOBENIN, I.A. et al. Lipid-lowering effects of timereleased garlic powder tablets in double-blinded placebo-controlled randomized study. Journal of Atherosclerosis and Thrombosis, v.15, n.6, p.334-8, 2008.

SPOSITO, A.C. et al. IV Diretriz Brasileira sobre dislipidemias e prevenção da aterosclerose. Arquivos Brasileiros de Cardiologia, v.88, suppl.1, 2007.

STAMLER, J. et al. The multiple risk factor intervention trial research group, diabetes, other risk factors and $12-y r$ cardiovascular mortality for men screened in the multiple risk factor intervention trial. Diabetes Care, v.16, p.434-44, 1993.

VERPOORTE, R. Reviews: Exploration of nature's chemodiversity: the role of secondary metabolites as leads in drug development. DDT, I v.3, n.5, p.232-38, 1998.

VICTORIO, C.P.; Lage, C.L.S. Uso de Plantas Medicinais. Revista Arquivos FOG - Saúde, Sociedade, Gestão e Meio Ambiente, v. 5, n.1, p.33-41, 2008. 
WARSHAFSKY, S. et al. Effect of Garlic on Total Serum Cholesterol - A Meta-analysis. Annals of Internal Medicine, v.119, n.7, p.599-605, 1993.

WHITNEY, N.E. Nutrition and disorders of the blood vessels, heart and lugs. In: Whitney, N.E.; Rolfes, S.R.; Pinna, K. Understanding normal and clinical nutrition. 4.ed. Minneapolis: West Publishing Company, chap.27, 1994, p.879-909. 